Аниськина Т.С., Наконечная Д.В., Симахин М.В., Донских В.Г. Полиморфизм количественных признаков морозника зеленого (Helleborus viridis L.)

\title{
УДК 58.018
}

\section{Полиморфизм количественных признаков морозника зеленого (Helleborus viridis L.)}

\author{
Аниськина Т.С. ${ }^{1}$, Наконечная Д.В. ${ }^{1}$, Симахин М.В. ${ }^{1,2}$, Донских В.Г. ${ }^{1}$ \\ ${ }^{1}$ ГБС им. Н.В. Цицина РАН \\ ${ }^{2}$ РГАУ-МСХА им. К.А. Тимирязева
}

\begin{abstract}
Аннотация
Морозники в ряде стран являются экономически важными декоративными культурами, а также эти растения - источники гликозидов, применяемых в медицинских целях. В литературных источниках не удалось найти информацию по изменчивости признаков Helleborus viridis L., а это необходимо знать при направленной селекции растений. Поэтому целью данной работь является анализ полиморфизма количественных признаков у морозника зеленого в коллекции Главного ботанического сада им. Н.В. Цицина (Москва, Россия). Сбор данных по количественным признакам провели в 2021 году. Отмечено 20 признаков, включая 2 признака габитуса растения, 8 признаков листа, по иветку - 6 и 4 у плода. Статистическую обработку данных провели, применив расчет коэффициентов вариаџии и проведя однофакторные дисперсионные анализы. Установили, что высокий процент полиморфизма приходится на параметры листа, а низкая изменчивость - у признаков ивветка и плода. Особенности генотипа на 20-30\% влияют на параметры листьев, а достоверного влияния на другие параметры не обнаружено.

Работа выполнена в рамках госзадания ГБС РАН 18-118021490111-5.

Ключевые слова: HELLEBORUS VIRIDIS L., MOРОЗНИК ЗЕЛЕНЫЙ, АНАЛИЗ ИЗМЕНЧИВОСТИ, КОРРЕЛЯЦИЯ, КОНТЕЙНЕРНОЕ ВЫРАЩИВАНИЕ
\end{abstract}

\section{Введение}

Морозник зеленый (Helleborus viridis L.) относится к семейству лютиковые. Является многолетним корневищным растением, которое распространено естественным 
Аниськина Т.С., Наконечная Д.В., Симахин М.В., Донских В.Г. Полиморфизм количественных признаков морозника зеленого (Helleborus viridis L.)

образом в Средней и Юго-западной Европе и Африке [1]. Надземная часть растения состоит из нескольких прикорневых листьев, цветоноса с несколькими цветками (1-4 шт), а подземная часть - из толстого короткого корневища и большого количества придаточных корней. Листья пальчато-рассеченные, основная масса сегментов листа цельная, но у краевых часто встречаются рассечения второго порядка. Особенностью морозника является то, что прикорневые листья появляются поздно - во время развития плодов, поэтому чашелистики являются основным источником ассимилянтов при фотосинтезе. В литературных источниках отмечено, что фотосинтетеческая активность органов морозника убывает в следующем порядке: лист, чашелистик, плод, стебель [2]. Цветки актиноморфные. Внешняя мутовка околоцветника состоит из 5 крупных чашелистиков, которые не опадают до конца плодоношения, внутренняя мутовка является эквивалентом лепестков - от 9 до 12 воронкообразных нектарников [3]. Плод многолистовка, семена черного цвета.

Классификация морозника отчасти затруднена из-за высокого полиморфизма и наличия переходных форм [4]. Но такая изменчивость позволяет растениям лучше приспособиться к различным условиям среды, а также использовать их в селекции для получения новых гибридов с ценными свойствами для декоративного садоводства и лекарственной промышленности. Высокий уровень индивидуальной изменчивости был отмечен рядом ученых в России, Испании [5, 6] у Helleborus caucasicus, H. abchacicus, H. foetidus, но исследований по изменчивости H. viridis проведено не было.

Ценится морозник в основном как источник стероидных гликозидов, сапонинов [7, 8], так же является экономически важным декоративным растением [9-11], поэтому часто его можно найти в коллекциях лекарственных и декоративных растений в ботанических садах. Известно, что разные виды морозников скрещиваются друг с другом $[9,10,12]$. Семена высеваются на коллекционные участки и прорастают, что ухудшает чистоту коллекции. Чтобы решить эту проблему, мы в Ботаническом саду имени Н.В. Цицина пересадили морозники в контейнеры, в литературе подобный опыт выращивания морозников для России еще не был описан, но есть опыт выращивания H. lividus [13]. Поэтому целью нашей работы стало изучение внутривидовой изменчивости $H$. viridis при выращивании в контейнерах. 
Аниськина Т.С., Наконечная Д.В., Симахин М.В., Донских В.Г. Полиморфизм количественных признаков морозника зеленого (Helleborus viridis L.)

\section{Методика}

Объектами изучения является коллекция морозника зеленого в ГБС РАН. В 2020 году растения были пересажены в контейнеры объемом 20 литров, в качестве субстрата использовали садовую землю. Укрытия на зиму не производили.

Описание вида провели в июле 2021 года по следующим 20-и количественным признакам [14]:

- параметры габитуса - высота и ширина растения (см);

- параметры листа - количество листьев (шт), высота листовой воронки (см), максимальная ширина листовой пластинки (см), максимальная длина листовой пластинки (см), количество листочков (шт), длина центрального листочка (см), ширина центрального листочка (см), длина черешка (см);

- параметры цветка - высота цветоноса (см), количество цветоносов (шт), количество цветков на цветоносе (шт), диаметр цветка (см), длина чашелистика (см), ширина чашелистика (см);

- параметры плода - длина плода (см), ширина плода (см), длина кончика плода (см), количество листовок (шт).

Внутривидовую изменчивость оценивали путем вычисления коэффициентов вариации, как среднее квадратическое отклонение деленое на среднее арифметическое. Чтобы определить степень внутривидовой вариации признака, мы воспользовались методикой Мамаева С.А., где очень низкий уровень изменчивости составляет 7-15\% вариации, средний - 16-25\%, повышенный - 26-35\%, высокий - 36-50\% и очень высокий более $50 \%$ вариации [15].

Для выявления причин внутривидовой вариации провели однофакторный дисперсионный анализ.

\section{Полученные результаты и их обсуждение}

a) анализ вариации признаков

Для производства контейнерной продукции, ландшафтного дизайна важно, чтобы растения были выровнены по ряду признаков. Поэтому в работе приведена оценка вариации количественных признаков морозника зеленого. Оказалось, что:

- $\quad$ низким (7-15\%) коэффициентом вариации обладают такие признаки, как 
Аниськина Т.С., Наконечная Д.В., Симахин М.В., Донских В.Г. Полиморфизм количественных признаков морозника зеленого (Helleborus viridis L.)

ширина куста (коэффициент вариации 11,9\%), длина чашелистиков (11,3\%), диаметр цветка (13,6\%), длина кончика плода (11\%), количество листовок (14\%);

- $\quad$ средняя степень изменчивости отмечена у большинства параметров - 11 признаков из 20и. В эту группу относятся высота куста (вариация 19,7\%), максимальная ширина листовой пластинки (22\%), количество лопастей $(15,8 \%)$, длина центральной лопасти $(23,9 \%)$, ширина центральной лопасти (18\%), длина черешка $(20 \%)$, высота цветоноса $(20 \%)$, ширина чашелистиков $(15,8 \%)$, длина плода $(15,7 \%)$, ширина плода $(24,1 \%)$

- $\quad$ повышенная вариация признаков у количества листьев (31\%), максимальной длины листовой пластинки (27,7\%), у количества цветоносов $(25,6 \%)$;

- $\quad$ высокий показатель вариации зафиксирован у высоты листовой воронки $(35,4 \%)$ и у количества цветков на побеге (39\%).

б) анализ влияния генотипа видообразца на изменчивость признаков, которые имеют нормальное распре

Известно, что разные виды морозников прекрасно скрещиваются друг с другом [9, $10,12]$. А пополнение коллекций ботанических садов часто происходит благодаря обмену семенами растений. Но не каждое семя имеет генотип именно чистого вида, это уже может быть межвидовой гибрид, так как коллекции видов морозника в ботанических садах не изолируют друг от друга. Поэтому, есть вероятность, что полученные нами семена имеют гибридное происхождение. А, следовательно, вариация признаков может быть обусловлена генотипом видообразца. Для того, чтобы понять причины вариации, мы провели однофакторный дисперсионный анализ о влиянии генотипа видообразцов на изменчивость количественных признаков и получили следующую информацию:

- высота листовой воронки в коллекции сильно варьировала, и удалось установить, что $31 \%$ вариации обусловлен влиянием генотипа.

Достоверно отличается образец Z-1-2 (средняя высота листовой воронки 6,8 см) от Z-1-4 (4,1 см), так как их попарная разница 2,65 превышает $\mathrm{HCP}_{05}=2,35$. Так же есть различия между парами образцов Z-1-2 и Z-1-8 (средняя высота воронки 2,45), Z-1-4 и Z1-6 (7,0 см), Z-1-6 и Z-1-8.

- максимальная ширина листовой пластинки - на 30 \% достоверно изменяется из-за 
Аниськина Т.С., Наконечная Д.В., Симахин М.В., Донских В.Г. Полиморфизм количественных признаков морозника зеленого (Helleborus viridis L.)

генетических особенностей. $\mathrm{B}$ выборке наибольшей максимальной шириной характеризуются образцы Z-1-2 (20,1 см), Z-1-7 (19,1 см), Z-1-3 (18,9 см), Z-1-4 (17,4 см). Достоверные различия обнаружены между вышеперечисленными образцами с Z-1-1 (12,7 $\mathrm{cm})$.

- максимальная длина листовой пластинки - на 21\% обусловлена влиянием генотипа. В выборке образцы Z-1-2 (18,2 см) и Z-1-3 (18,9 см) имеют максимальное значение признака, соответственно эти образцы достоверно отличаются от Z-1-1 (10,6 см) и Z-1-8 (12,4 см). остальные образцы статистически схожи.

- количество листочков - обнаружено достоверное влияние генотипа на 15\% с 95\% вероятностью, с вероятностью 99\% утверждать мы этого не можем.

- длина центрального листочка - вариация этого признака на 43\% обусловлена влиянием генотипа. Образец Z-1-1 (средняя длина центральной лопасти 7,1 см) достоверно отличается от образцов Z-1-2 (12,2 см), Z-1-3 (10,9 см), Z-1-5 (10,3 см), Z-1-6 (10,1 см), Z-1-7 (11,3 см). А образец Z-1-2 отличается от Z-1-4 (9,6 см) и Z-1-8 (8,2 см), так как их попарная разница больше $\mathrm{HCP}_{05}=2,57$.

- ширина центрального листочка - на 29\% вариация обусловлена генотипом, достоверные отличия в выборке обнаружены также у образца Z-1-1 со всеми, кроме Z-1-4 (3,9 см) и Z-1-8 (4,1 см).

- длина черешка у прикорневого листа - наименьшего размера у образца Z-1-1 (11,7 см), что делает его достоверно отличимым от образцов Z-1-2 (17,6 см), Z-1-3 (15,9 см), Z1-5 (15 см), Z-1-6 (15,5 см), Z-1-7 (16,6 см). На 43\% вариация обусловлена генотипом.

Достоверного влияния генотипа не обнаружено на высоту цветоноса, количество цветков, диаметр цветка, на длину и ширину чашелистиков, а также на длину и ширину плода, количество листовок, длину кончика плода. Как показано было выше вариация этих признаков является низкой.

Результаты нашей работы по изменчивости листа согласуются с работой исследователей из Испании на Helleborus foetidus, нам также удалось подтвердить высокую изменчивость параметров листьев морозника у вида Helleborus viridis [6]. В работе ученых из России [5] на $H$. caucasicus и $H$. abchasicus, так же каки у нас на $H$. viridis установлено, что генеративные признаки имеют низкую вариацию. 
Аниськина Т.С., Наконечная Д.В., Симахин М.В., Донских В.Г. Полиморфизм количественных признаков морозника зеленого (Helleborus viridis L.)

\section{Выводы}

1. Низкая вариабельность количественных признаков отмечена у ширины растения (коэффициент вариации 11,9\%), длины чашелистиков $(11,3 \%)$, диаметра цветка $(13,6 \%)$, длина кончика плода (11\%) и у количества листовок;

2. Высокая вариация как в опыте, так и в литературных источниках у таких признаков, как количество листьев (31\%), максимальная длина листовой пластинки $(27,7 \%)$, количество цветоносов $(25,6 \%)$;

3. Внутривидовая изменчивость параметров листа на $20-30 \%$ обусловлена влиянием генотипа. А на параметры цветка достоверного влияния генотип не оказывает.

Работа выполнена в рамках госзадания ГБС РАН «Биологическое разнообразие природной и культурной флоры: фундаментальные и прикладные вопросы изучения и сохранения», номер госрегистрации 18-118021490111-5.

\section{Список использованных источников}

1. GBIF Backbone Taxonomy. Helleborus viridis L. in GBIF Secretariat (2021). [Электрон. pecypc] https://doi.org/10.15468/39omei accessed via GBIF.org on 2021-11-11.

2. Aschan G., Pfanz H., Vodnik D., Batic F. Photosynthetic performance of vegetative and reproductive structures of green hellebore (Helleborus viridis L. agg.) // Photosynthetica. 2005. - № 43 (1). - P. 55-64.

3. Brian Mathew, Hellebores, Alpine Garden Society, 1989 - ISBN 0-900048-50-6

4. Fico G., Servettaz O., Caporali E., Tomè F., Agradi E. Investigation of Helleborus genus (Ranunculaceae) using RAPD markers as an aid to taxonomic discrimination // Acta Horticulturae. - 2005. -№675. - P. 205-209.

5. Гулия В.О., Орловская Т.В. Морфолого-анатомическое исследование генеративных органов Helleborus caucasicus и Helleborus abchasicus // Современные проблемы науки и образования. - 2014. - №6. - 1367

6. Herrera C.M., Medrano M., Bazaga P. Continuous within-plant variation as a source of intraspecific functional diversity: patterns, magnitude, and genetic correlates of leaf variability in Helleborus foetidus (Ranunculaceae) // American Journal of Botany. - 2015. - № 102 (2). - P. $225-232$.

7. Stochmal A., Perrone A., Piacente S., Oleszek W. Saponins in aerial parts of Helleborus viridis L. // Phytochemistry Letters. - 2010. - № 3(3). - P. 129-132.

8. Braca A., Prieto J., De Tommasi N., Tomè F., Morelli I. Furostanol saponins and 
Аниськина Т.С., Наконечная Д.В., Симахин М.В., Донских В.Г. Полиморфизм количественных признаков морозника зеленого (Helleborus viridis L.)

quercetin glycosides from the leaves of Helleborus viridis L. // Phytochemistry. - 2004. - № 65 (21). - P. 2921-2928.

9. Meiners J., \& Winkelmann T. Evaluation of reproductive barriers and realisation of interspecific hybridisations depending on genetic distances between species in the genus Helleborus // Plant Biology. - 2012. - № 14 (4). - P. 576-585.

10. Šušek A. Perspectives of Christmas rose (Helleborus niger L.) genetic improvement // Agricultura. - 2017. - № 13 (1-2). - P. 11-19.

11. Christiaens A., Dhooghe E., Pinxteren D., Van Labeke M.C. Flower development and effects of a cold treatment and a supplemental gibberellic acid application on flowering of Helleborus niger and Helleborus x ericsmithi // Scientia Horticulturae. - 2012. - № 136. - P. $145-151$.

12. Winkelmann T., Hartwig N., Sparke J. Interspecific hybridisation in the genus helleborus // Acta Horticulturae. - 2015. - №1087. - P. 301-307.

13. Henschke M., Szczepaniak S., Czuchaj P., Kozik E. The effect of calcium carbonate and top dressing with Peters Professional Special on the growth and flowering of Helleborus lividus Aiton // Folia Horticulturae. - 2009. - 21 (1). - P. 105-117.

14. Исачкин А.В., Крючкова В.А. Математическое моделирование формы листовой пластинки растений // Математическое и компьютерное моделирование в биологии и химии. - 2014. - С. 73-76.

15. Мамаев С.А. Основные принципы методики исследования внутривидовой изменчивости древесных растений // Индивидуальная и эколого-географическая изменчивость растений. - 1975. - С. 3-14.

\section{Цитирование:}

Аниськина Т.С., Наконечная Д.В., Симахин М.В., Донских В.Г. Полиморфизм количественных признаков морозника зеленого (Helleborus viridis L.) [Электрон. pecyрс] // АгроЭкоИнфо: Электронный научно-производственный журнал. - 2021. - №6. - Режим доступа: http://agroecoinfo.ru/STATYI/2021/6/st_611.pdf.

DOI: https://doi.org/10.51419/20216611. 